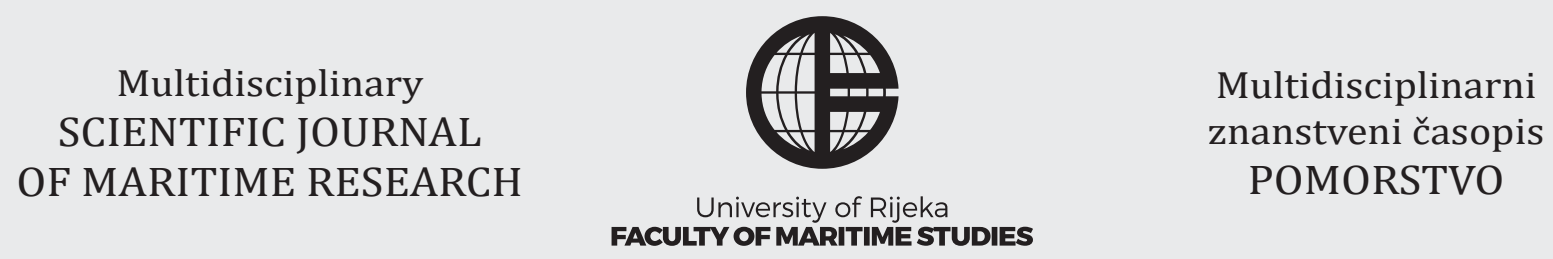

\title{
Analysing volatility spillovers between grain and freight markets
}

\author{
Totakura Bangar Rajuㅅ, Ayush Bavise ${ }^{1}$, Pradeep Chauhan, Bhavana Venkata Ramalingeswar Rao ${ }^{2}$ \\ ${ }^{1}$ School of Business, University of Petroleum and Energy Studies, Kandholi, Via-Prem Nagar, Dehradun - 248007, Uttarakhand State, India, \\ e-mail: bangarraju@gmail.com; aayush.bavise02@gmail.com; pradeep.chauhan.ddun@gmail.com \\ ${ }^{2}$ Indian Maritime University, Visakhapatnam new campus, Vangali Village, Tekkalipalem Post, Near Rayavarapu Agraharam, Sabbavaram, Visakhapatnam - \\ 531035, Andhra Pradesh State, India, e-mail: profbhavana@gmail.com
}

\section{ABSTRACT}

The International Grain Council (IGC) circulates two price indices which are the Grain and Oilseeds Index (GOI) and the Grain and Oilseeds Freight Market Index (GOFI). These two indices indicate the respective market prices. The GOI markets are affected by various factors like supply and demand, weather, freight markets, etc. This research article attempts to explore and analyse volatility in GOI and GOFI markets using various GARCH family models, that is Exponential Generalized Autoregressive Conditional Heteroskedasticity (EGARCH) analysis. The multivariate Dynamic Conditional Correlation Generalized Autoregressive Conditional Heteroskedasticity model (DCC GARCH) is used to find the spillovers between the two markets and thereby explore the effect of GOFI on GOI markets from the year 2013. The research article consists of four sections after introducing the subject namely a literature review, research methodology and models, analysis and conclusions of the study.

\section{ARTICLE INFO}

Preliminary communication

Received 9 March 2020

Accepted 21 November 2020

\author{
Key words: \\ Volatility \\ GARCH \\ Grain markets \\ Freight markets \\ Spillovers
}

\section{Introduction}

The dry bulk cargo, consisting of transportation of grains is a significant constituent of international shipping that also carries with itself elements of volatility and risk. This uncertainty is caused by the pattern of global trade, size of the business, market forces of supply and demand, the global economy and policies of various governments. In this extremely competitive market, the substantial volatility of freight rates makes it challenging to predict the trend, thus bringing in its wave high risks as well as opportunities to the parties involved. Compared to other sectors of the economy, the agriculture sector experiences excessive volatility. As pointed out earlier grains and oilseeds have a continuous fluctuation in global supplies that are primarily governed by crop production cycles, weather, and on-going changes in global demand. This volatility in the grains and oilseeds prices impacts the market of developing countries more, with severe implications for farmers and low-income consumers. Both consumers and producers are affected by volatility and changing prices of the commodities. For example, low-income consumers spend a large share of their disposable income on food, mostly on essential foods, making them more vulnerable to the risk of food price volatility. The volatility study is also required for farmers who rely on selling prices of their grains harvested (Tadesse et al., 2016).

\subsection{World Grain and Oilseeds Market}

The IGC GOI is obtained from the (Council, 2019b) from $1^{\text {st }}$ January 2013 till $24^{\text {th }}$ September 2019. The second time series, the weekly international GOFI is obtained from the (Council, 2019c) from $1^{\text {st }}$ January 2013 till 24 $4^{\text {th }}$ September 2019.

The (International Grain Council, 2020) put total grains (wheat and coarse grains) production in 2019-20 at 2.1 billion tonnes, with a growth of one per cent from the previous year (2018-19), as demand for crops of wheat and barley outweighed a decline for maize. increased, the total global grains harvested in 2019-20 is expected to be the secondlargest ever, at 2.17 billion tonnes with an increase of one per cent in 2019-20. The consumption wheat for food, feed, 


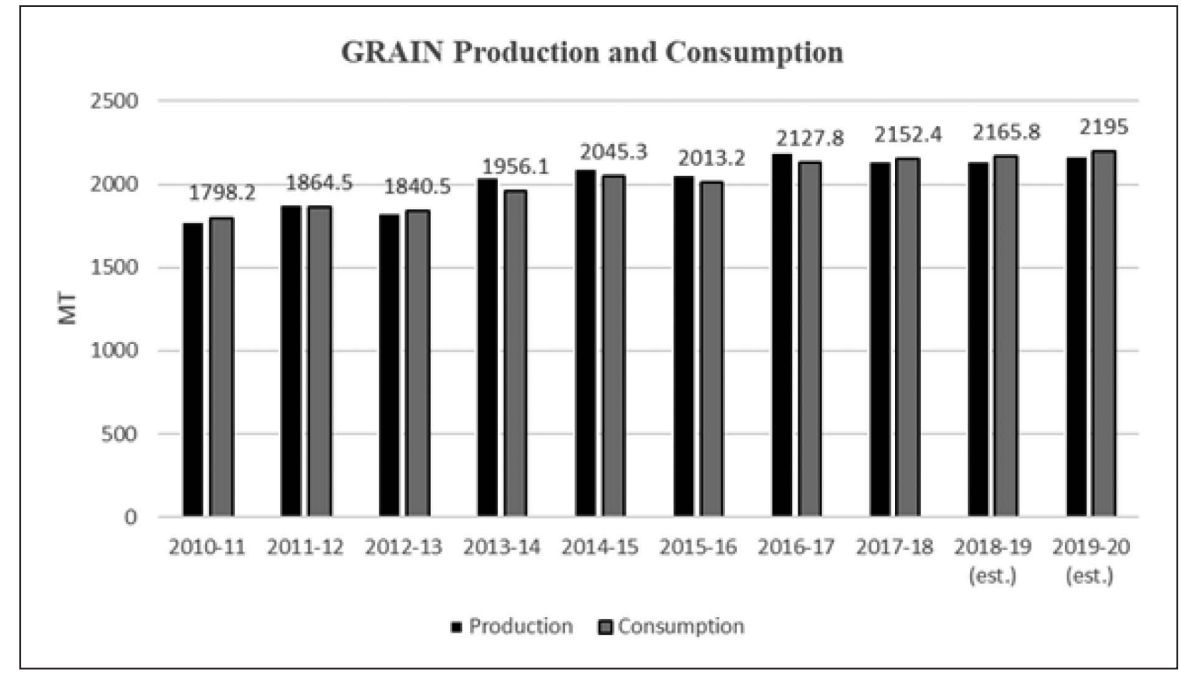

Figure 1 Production vs Consumption

Source: (Council, 2019a)

and industrial purposes is expected to increase by two per cent. Supply and demand projections point to a larger global wheat harvest and, while consumption growth is assumed, there could be an increase in the closing stock at the end of the season. With inventory, growth continued to be centred on China and India. The global wheat harvested area in 2020-21 increased by one per cent according to the IGC Report with the rise in wheat production in India. A third successive decrease in world grains stocks is predicted, to a five-year low of 592 million tonnes which is a decrease in 27 million tonnes from the previous year. This decrease is because of a contraction of maize inventories for the last six seasons, which is primarily linked to reductions to Maize demand in the USA and China.

The figure above (Figure 1) shows the data of a decade of production and total consumption of grains. We can see the difference between the consumption and production of grains - the demand for grains is more than the supply of grain. For the year 2019-20, the forecast hereby indicates the total consumption will be more than the total production of the grains and oilseed in the market. The reason for the difference in supply and demand of grains and oilseed is the increase in the population and decreasing yield of grain.

\subsection{IGC GOI Index}

Worldwide grain and oilseeds commodity prices signify variations in supply and demand in major consuming and producing, importing and exporting countries. They also signify a change in policies, such as strengthening trade dealings or variations in governmental stocking and purchase measurements, which have demonstrated to be essential factors of food prices and their volatility at the global level.

Figure 2 indicates the GOI from 1 January 2013 to 24 September 2019. There is an increase in the world total

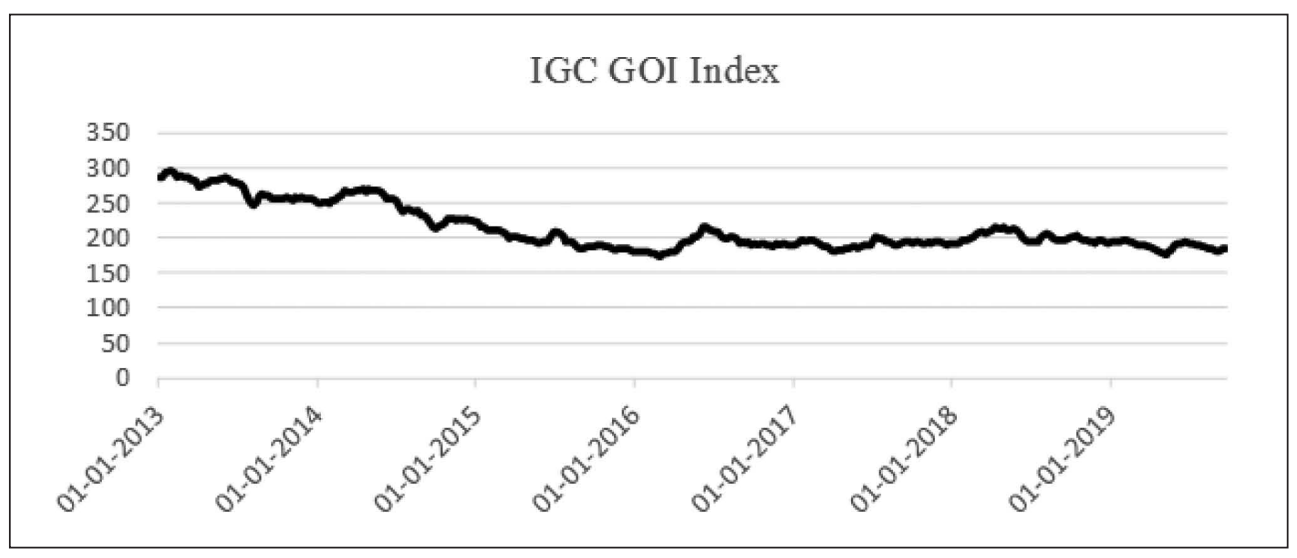

Figure 2 IGC Grain and Oilseed Index (2013-2019) 
grains production in 2019-20 to 3.3 per cent to 2,170 MT. The world total of grain production has moved upward from the month of November 2019 and is expected to grow at one per cent from the previous year with assumed consumption growth in the year 2020-21 (IGC, 2020). The report (CME Group, 2019) enlists in detail various factors which affect the volatility of IGC GOI index such as freight rates, grains supply and demand, weather, price of raw materials, disposable income, population growth, currency exchange rate, consumer preferences and consumption trend.

\subsection{IGC Freight Index (GOFI)}

The IGC Secretariat compiles weekly data on nominal ocean freight rates for a wide range of grains and oilseeds (wheat, rice, maize, barley, soya beans). The GOFI covers 68 routes from key exporting origins, including Argentina, Australia, Brazil, the Black Sea, Canada, the EU, and the USA. The index is constructed using a weighted average approach, with each route assigned a weighting based on its previous year's share in the total flow of all commodities considered.

The below figure (Figure 3) shows the IGC GOFI from January 2013 to October 2019, with an annual change of $-27 \%$. We can understand that the freight index is volatile. It has seen a decline in freight at the starting of the financial year 2019-20, but the freight rate grew immensely from June 2019, 157 being the highest, and 106 being the lowest. IGC GOFI builds significantly on the prior measure. GOFI is calculated weekly starting from January 2013, taken as base of 100 .

\section{Literature review}

The early volatility in various traded goods in Australia are analysed using GARCH models (Woodland and Sen, 2010 ) to estimate the volatility in various goods of import and export in Australia. A strong presence of correlation among each of these goods and time-varying volatility is suggested by the authors. The various determinants of volatility in commodities like wheat, soya bean, corn, and oats have also been studied (Thurman, 2010) where generalised least squares method has been used to find the seasonality, time-to-delivery effects, trend persistence of volatility. Uncertainty and risk in world grain markets are discussed in another interesting study(Hill, Lazarus, and Wiboonspongse, 2010). Instabilities in world supplies and prices, alternatives for reducing volatility, cartel in world grain markets, and various aspects of risk as a facilitating function have been reviewed. The future performance of the grain market has been evaluated to mitigate risk (Santos, 2011) where the author has attempted to test the efficiency of a commodity market for wheat, corn, and oats. Wheat markets were found to be efficient in the short-run, oats markets were found to be inefficient. The various aspects of grain price volatility and multiple challenges faced by economists to understand the economic phenomenon behind the grain price volatility have been analysed (Wright, 2011). The study shows that some tools could give guidance for policymakers for better prescription, but there is a need to learn much more about the commodity markets. Exports restrictions play a role on grain and oilseed price volatility (Rude and An, 2015). The presence of strong volatility was found for wheat and rice prices. However, soya bean and maize prices were not found to have volatility impacts due to export restrictions. GARCH models have been used to analyse the spillo-

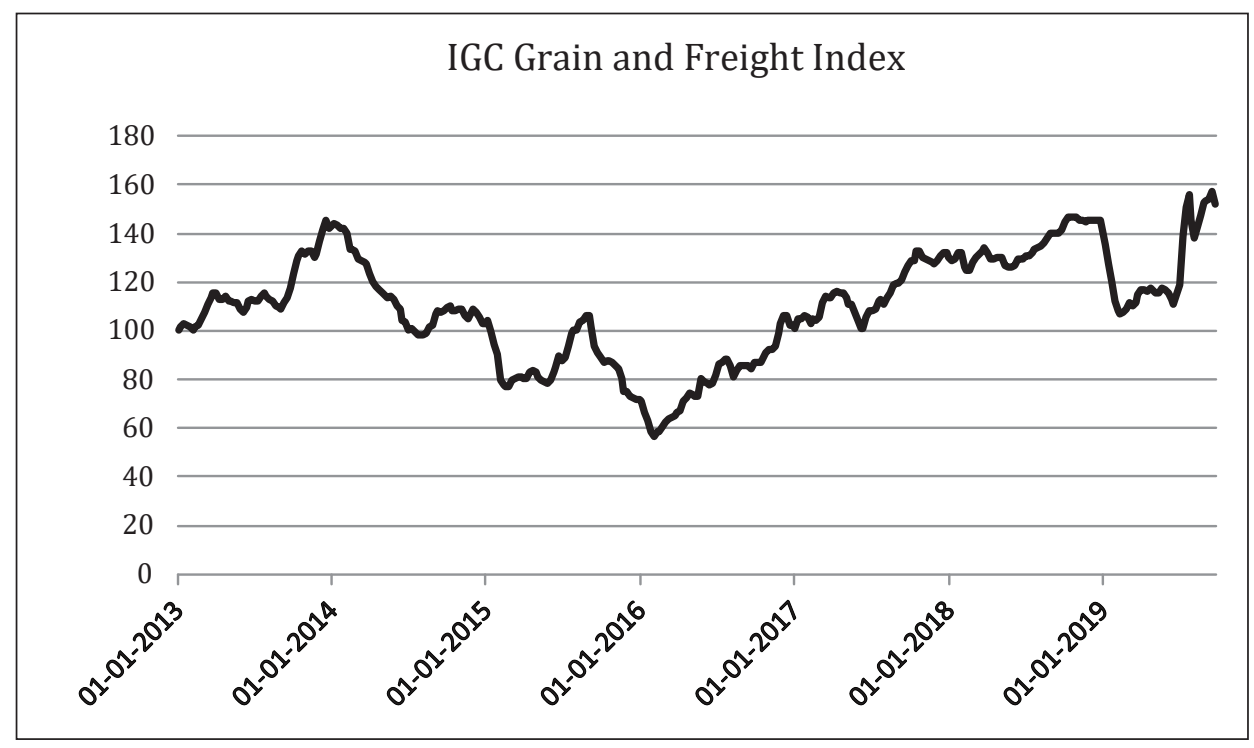

Figure 3 IGC Grain and Oilseed Freight Index (2013-2019) 
vers between international and domestic food products (Ceballos et al., 2017). Results from multivariate GARCH model analysis indicate the presence of volatility transmission when imports and exports are mainly for domestic needs.

This section discusses various studies done regarding dry bulk freight rates. Grains are generally categorised under dry bulk shipping markets for transportation by sea. The relationship between spot and period freight rates, which is also referred to as term structure, is explored (Veenstra, 1999). Vector autoregressive (VAR) model has been used to find the term structure in the freight markets. Results suggest the presence of relation between period and spot freight rates. The deterministic, stochastic nature of seasonality in dry bulk freight rates among various vessel sizes has also been investigated (Kavussanos and Alizadeh-M, 2001). Evidence from the paper suggests the absence of stochastic seasonality. However, the presence of deterministic seasonality was found to be more present in larger vessels for spot rates. The application of GARCH and EGARCH models to investigate volatility in various Baltic dry indexes have been made (Jing, Marlow, and Hui, 2008) which suggested a strong presence of asymmetric effects across various market conditions and were distinctive for various vessel sizes.

Similar GARCH family-like models with cross-sectional volatility which are known as GARCHX and EGARCH models were used for understanding time-varying volatility in Baltic dry indexes (Drobetz, Richter, and Wambach, 2012). However, in contrast to previous studies, asymmetric effects were found to be absent in the dry bulk markets. Volatility in forwarding freight agreements in dry bulk markets is done in a study (Alizadeh, 2013) whereby the statistical model VAR and Exponential EGARCH models have been used, and it was found that a rise in volatility lead to decrease in future trading activities in the forward freight agreements. Multivariate GARCH models have also been used (Tsouknidis, 2016) to find the volatility spillovers in the Baltic dry indexes. The results from the paper suggest the presence of large spillovers in the dry bulk indexes and more intense spillovers during the financial crisis which started in 2007. Similarly, univariate GARCH models and Granger causality models have been used to understand the dynamics and interdependencies in various Baltic dry indexes ( $\mathrm{Li}$ et al., 2018).

A different method, the Iterated Cumulative Sum of Squares (ICSS) algorithm and Multifractal detrended fluctuation analysis (MF-DFA) method has been employed to study freight rate volatility under structural breaks in an exploratory paper (Ding et al., 2017). From the results, the Baltic Supramax was found to have a more substantial long-term correlation. The relationship between commodity markets and risk attitude in shipping markets have been analysed (Ishizaka, Tezuka and Ishii, 2018) whereby structural equation modelling has been used to test the applicability of calibrated risk attitude. The MF-DFA meth- od was also used to find the asymmetric effects in the dry shipping market during the financial crisis of 2012 (Liu and Chen, 2018) which suggested that economic shocks have the influence of different magnitude on various types of vessels, and the variation of breaking points was also found. That implied volatility was affected by the slope of the forward curve, spot rate, supply factors, and demand factors was suggested in the study made to understand various drivers of volatility in freight markets (Lim, Nomikos, and Yap, 2019).

One of the early studies attempted econometric analysis of understanding determinants of ocean freight rates of grain (Binkley and Harrer, 1981) where the role of transportation in grain freight rates was brought forward, and it was found that trade volume and size of the ships are as crucial as voyage distance in determining freight rates. The VAR model has been used to find the dynamic linkages in the ocean grain transport (Hsu and Goodwin, 1995) in which the model contained grain shipments, ocean grain freight rates, new carrier deliveries, idled tonnage, and fuel prices. The results suggest that ocean freight rates were receptive to new ship deliveries and fuel prices but not affected by demand shocks. A new econometric model has been used for barge and rail freight market to understand various factors affecting the freight rates of barge and rail for export-bound grain in the Mexican Gulf region (Miljkovic et al., 2000). From the results, many factors were found to be significant.

The vector error correction GARCH-M model has been used to explore time-varying volatility in river barge and ocean freight rates of Mississippi river over Illinois commodity prices, in Rotterdam and at the US Gulf (Haigh and Bryant, 2001). Results suggest the existence of barge and ocean freight volatility affect the prices of the grain. Volatility due to barge freight prices were found to have a greater impact than ocean freight prices. GARCH models have also been used to explore various significant factors affecting the ocean freight rates of grain (Jonnala, Fuller, and Bessler, 2002) where the results indicate carrier size and voyage distance were significant factors affecting the ocean grain rates. However, very high port costs and effects of larger carriers bring forward the need for enormous infrastructure to handle the grain shipments. The need for improving better infrastructure to support transportation which would, in turn, increase the competitiveness of world grain markets was also brought forward (Fuller et al., 2008) and VAR and Error Correction (ECM) models have been used to explore the price linkages between transportation markets and US grain prices in the Mississippi Gulf region. Results suggest that corn markets are affected by grain barge transportation rates. Fuzzy Analytic Hierarchy process (AHP) method has been used to study importer's and shippers' freight transport choice (Lirn and Wong, 2012) and the most critical aspect found in the study was that the overall costs of transportation played an essential role in influencing freight choice behaviour. 
Authors Manolis and Dimitris have also used various Baba-Engle-Kraft-Kroner model of Vector error correction model for Generalised Autoregressive conditional heteroskedasticity BEKK VECM-GARCH models to understand the volatility spillovers between various Freight Forward Agreements (FFAs) based on Baltic dry cargo indexes and commodity futures markets (Kavussanos, Visvikis, and Dimitrakopoulos, 2014). The results from the paper suggest that volatilities due to news affect commodity markets first, and spillovers are later seen on freight derivative markets. A closer look at the above literature review shows that GARCH models have been widely used to understand the transmission of volatility in the commodity and freight rates relationship analyses. As far as we know, no previous research has investigated the relationship between IGC GOI and IGC GOFI.

\section{Research methodology, models, and data}

EGARCH model $(1,1)$ as per (Nelson, 1991) is deployed to explore the volatility and leverage effect in both the time series. The conventional GARCH $(1,1)$ model cannot capture the asymmetric nature of volatility, that is, negative shocks having more impact compared to the positive shocks. The EGARCH is able to capture the asymmetric nature of the volatility. It is given by

$$
r_{t}=u+\phi_{1} r_{t-1}+\theta_{1} \epsilon_{t-1}+\epsilon_{t}
$$

where $\epsilon_{t}=\sigma_{t} z_{t}$ and $Z_{t}$ is standard normal.

$$
\ln \left(\sigma_{t}\right)^{2}=\omega+\alpha\left[\left|z_{t-1}\right|-E\left(\left|z_{t-1}\right|\right)\right]+\gamma z_{t-1}+\beta \ln \left(\sigma_{t-1}\right)^{2}
$$

The GARCH family models require that the series under analysis is stationary, that is, the series should not have any unit-roots. Augmented Dickey-Fuller (ADF) test (David A. Dickey and Wayne A. Fuller, 1981) has been used to find the unit root in the time series. To find the spillovers between both the time series DDC GARCH model (Engle, 2002) is used.

\section{Analysis}

The unit root test results based on the ADF test is given below in Table 1. First, we apply the test in the log level

Table 1 Augmented Dickey-Fuller (ADF) Test results in Log Level

\begin{tabular}{|c|c|c|c|c|}
\hline & Test Statistics & $\mathbf{1} \%$ Critical value & $\mathbf{5} \%$ Critical value & $\mathbf{1 0} \%$ Critical value \\
\hline IGC GOFI & 0.30 & -2.58 & -1.95 & -1.62 \\
\hline IGC GOI & -1.28 & -2.58 & -1.95 & -1.62 \\
\hline
\end{tabular}

Source: Author's own analysis

Table 2 Augmented Dickey-Fuller Test in First Difference

\begin{tabular}{|c|c|c|c|c|}
\hline & Test Statistics & $\mathbf{1} \%$ Critical value & $\mathbf{5} \%$ Critical value & $\mathbf{1 0} \%$ Critical value \\
\hline IGC GOFI & -9.58 & -2.58 & -1.95 & -1.62 \\
\hline IGC GOI & -10.28 & -2.58 & -1.95 & -1.62 \\
\hline
\end{tabular}

Source: Author's analysis

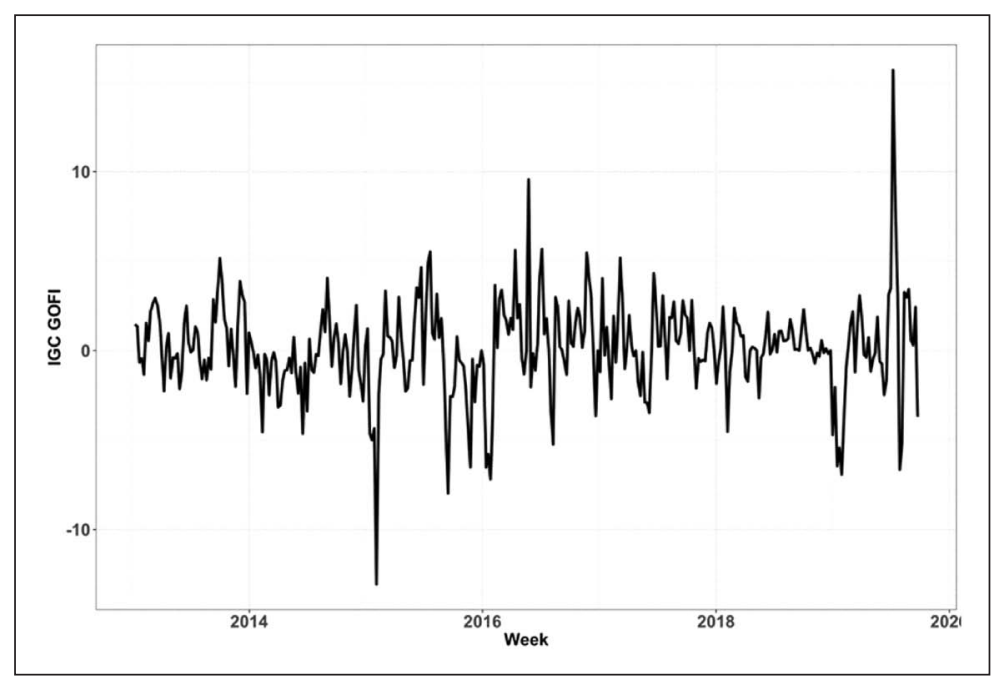

Figure 4 First difference of IGC GOFI 


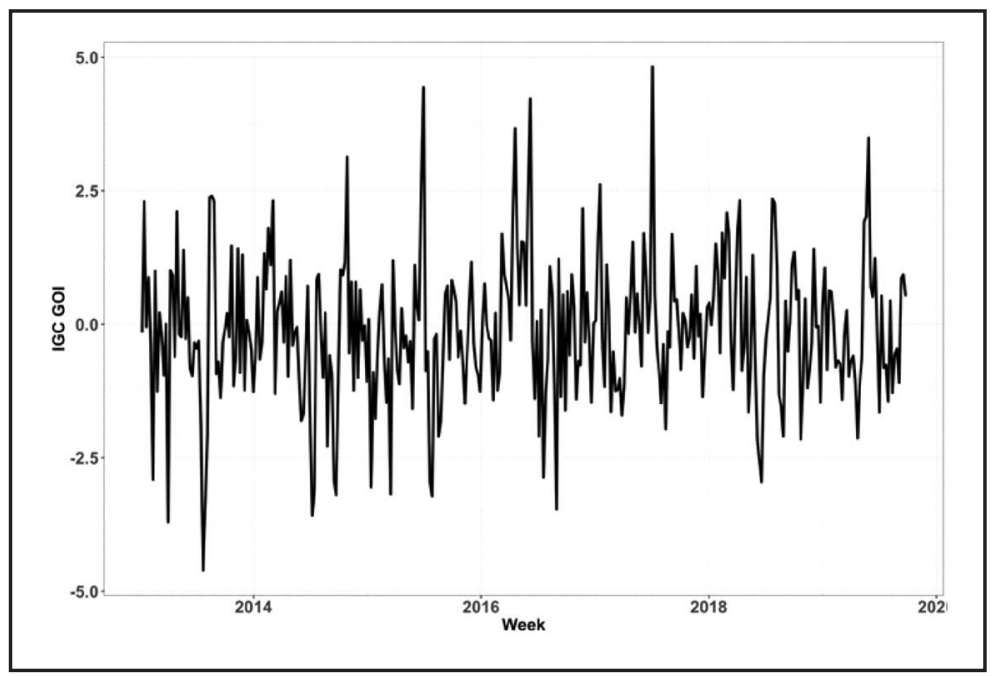

Figure 5 First difference of IGC GOI

Source: Author's analysis

series. The logarithm is taken to avoid the scale differences. The ADF test regresses the series on its lagged values. To find the optimal lag length, we employ Bayes Information Criteria (BIC). The lag at which BIC is minimised is taken as the optimal lag. Here, an optimal lag length of 8 is selected.

Based on the ADF test in level, all variables have a unit root. That is, all the series are stationary. Therefore, we take the first difference of the log level series and apply the unit root test on the differenced series. Here, BIC was used to find the optimal lag length of 8.

Based on the ADF test, the variables have been stationary in the first difference. Figure 4 and Figure 5 show the results for the first difference of IGC GOFI and IGC GOI, respectively. The stationary at first difference implies that the series revolves around the mean value after taking the first difference. Hence, we use the differentiated series for volatility modelling. First, the EGARCH $(1,1)$ result for IGC GOFI results are discussed below in Table 3, which give univariate EGARCH results and shows how volatile the series is.

Here, the ARCH effect is found to be statistically insignificant, whereas the GARCH effect is found to be significant and persistent. The conditional volatility is found to be influenced by its own lagged values. Further, the asymmetry parameter $\gamma$ is found to be significant, indicating the asymmetric nature of the volatility. After the model estimation, two post estimation diagnostic tests, that is the Ljung-Box test and ARCH LM test results on the model residuals are carried out. The results are given below in Table 4 .

Table 3 EGARCH Estimate for IGC GOFI

\begin{tabular}{|c|c|c|c|c|}
\hline Parameter & Value & Std. Error & t value & Pr (>t) \\
\hline$\mu$ & 0.20 & 0.06 & 3.25 & 0.00 \\
\hline$\phi_{1}$ & 0.49 & 0.04 & 11.65 & 0.00 \\
\hline$\theta_{1}$ & 0.00 & 0.00 & 1.94 & 0.05 \\
\hline$\alpha$ & 0.29 & 0.15 & 1.97 & 0.05 \\
\hline$\beta$ & 0.03 & 0.08 & -0.34 & 0.73 \\
\hline$\gamma$ & 0.84 & 0.08 & 10.07 & 0.00 \\
\hline
\end{tabular}

Source: Author's analysis

Table 4 Results of Ljung-Box Test and ARCH LM Test for IGC GOFI

\begin{tabular}{|l|c|c|}
\hline & Statistics & P-value \\
\hline Weighted Ljung-Box Test on Standardised Residuals Lag 1 & 0.3073 & 0.5794 \\
\hline Weighted Ljung-Box Test on Standardized Squared Residuals Lag 1 & 0.4098 & 0.5221 \\
\hline Weighted ARCH LM Tests Lag 3 & 0.7828 & 0.3763 \\
\hline
\end{tabular}




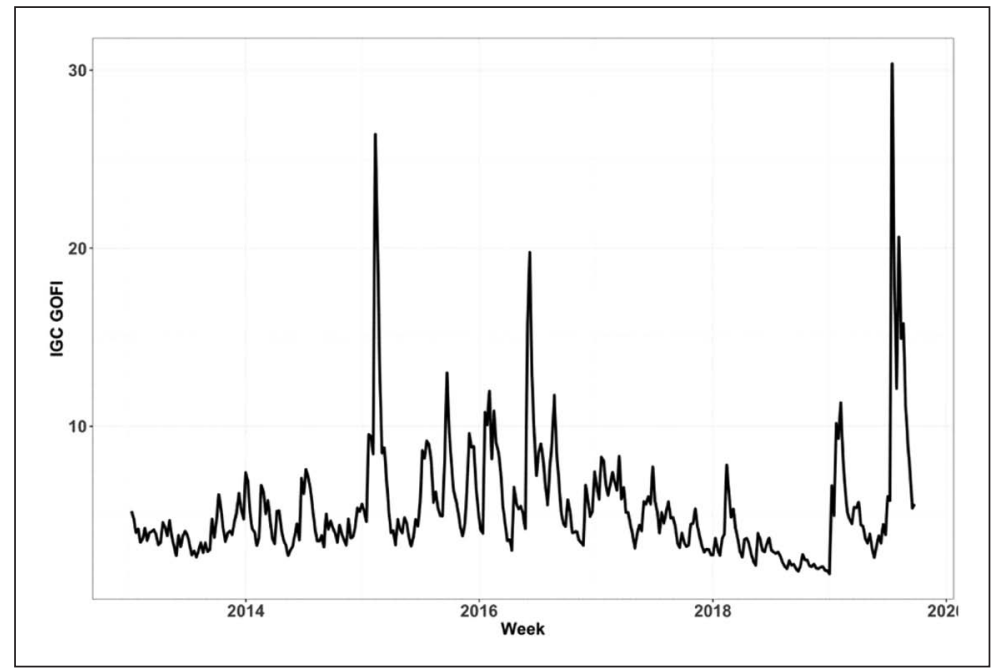

Figure 6 Conditional volatility in GOFI

Source: Author's analysis

The null of no autocorrelation among residuals and squared residuals is not rejected. Null of no ARCH effect could not be rejected. Hence it could be said that the model was able to capture the volatility dynamics of the given series. The conditional variance of IGC GOFI is given in Figure 6. Conditional volatility is the volatility estimated using the EGARCH model for the series IGC GOFI.

Next, the EGARCH estimates for IGC GOI are discussed in Table 5.

The conditional mean return on GOI is -0.14 . The moving average term is -0.08 . The autoregressive term for the first difference is .36. The persistence in GOI series is less than the GOFI series, as evidenced by the GARCH parameter. The GOI is half volatile compared to the GOFI series, as per the GARCH parameter values. Here too, the asymmetric nature of volatility is confirmed by the statistically significant gamma parameter. Next, we report the post estimation diagnostic test results, discussed below in Table 6 .

Null of no autocorrelation among residuals and squared residuals is not rejected. Null of no ARCH effect could not be rejected. Hence the model is able to capture the volatility dynamics.

Table 5 EGARCH Estimate for IGC GOI

\begin{tabular}{|c|c|c|c|c|}
\hline Parameter & Value & Std. Error & t value & Pr (>t) \\
\hline$\mu$ & -0.14 & 0.09 & -1.61 & 0.11 \\
\hline$\phi_{1}$ & 0.36 & 0.10 & 3.62 & 0.00 \\
\hline$\theta_{1}$ & -0.08 & 0.12 & -0.68 & 0.50 \\
\hline$\alpha$ & 0.68 & 0.18 & 3.72 & 0.00 \\
\hline$\beta$ & 0.05 & 0.07 & 0.75 & 0.45 \\
\hline$\gamma$ & 0.42 & 0.24 & -1.74 & 0.08 \\
\hline
\end{tabular}

Source: Author's own analysis

Table 6 Ljung-Box Test and ARCH LM Test results for GOI

\begin{tabular}{|l|c|c|}
\hline & Statistics & P-value \\
\hline Weighted Ljung-Box Test on Standardized Residuals Lag 1 & 0.03539 & 0.8508 \\
\hline Weighted Ljung-Box Test on Standardized Squared Residuals Lag 1 & 0.2171 & 0.6413 \\
\hline Weighted ARCH LM Tests Lag 3 & 0.09395 & 0.7592 \\
\hline
\end{tabular}




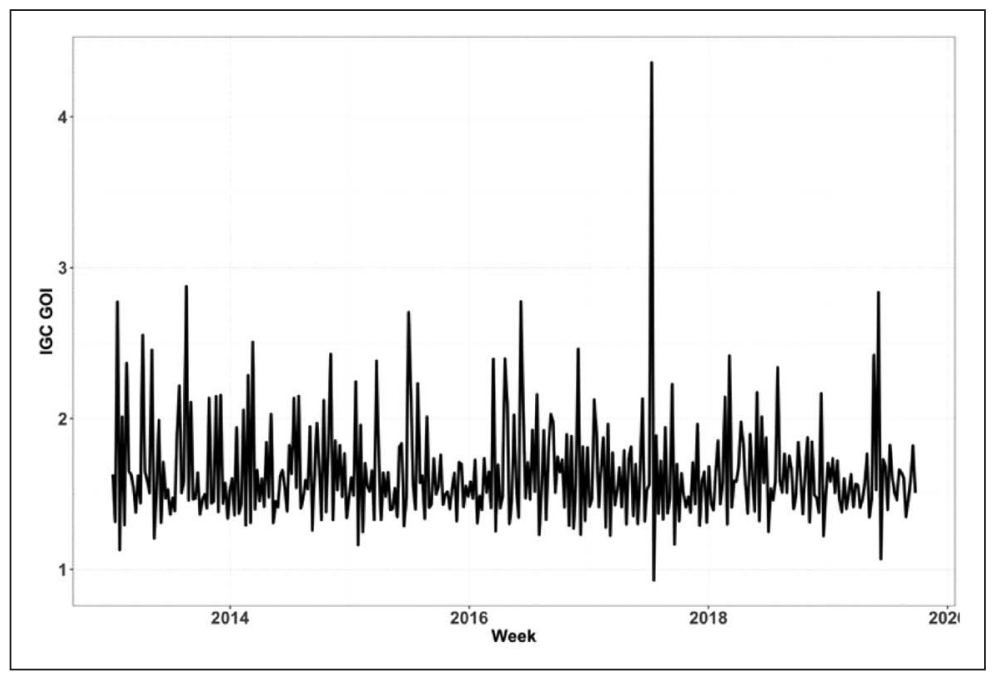

Figure 7 The conditional volatility in IGC GOI

Source: Author's analysis

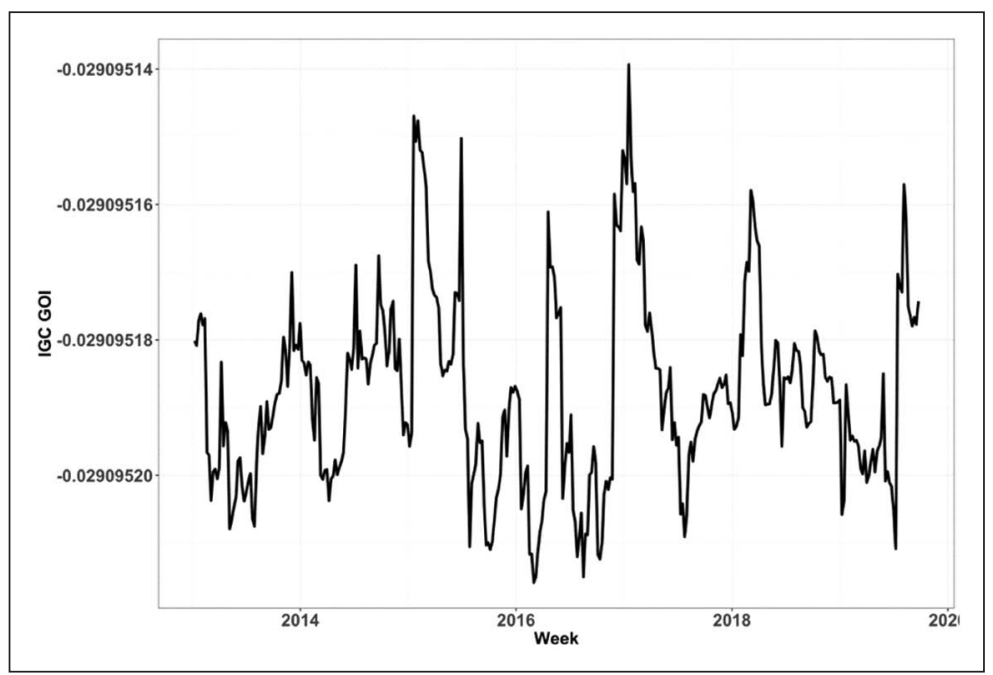

Figure 8 Correlation between IGC GOFI and IGC GOI

Source: Author's analysis

The conditional variance of IGC GOI is given above in Figure 7. Conditional volatility is the volatility estimated using the EGARCH model for the series IGC GOI.

Above in Figure 8, we plot the dynamic conditional correlation of IGC GOFI with IGC GOI using the DCC GARCH model. The dynamic conditional correlation of IGC GOFI with IGC GOI is very small and negative. This implies that there are very limited spillovers between the two markets.

\section{Conclusion}

The results indicate that GOFI has higher volatility than GOI markets. The persistence in GOFI was also found to be higher than GOI. The research result would presumably help commodity traders in grain and oil mar- kets, risk management professionals in grains markets, shipping lines, and freight forwarders to understand that impact of GOI and GOFI markets have limited and minimal impact on each other markets. However, the volatility of both the markets are different in nature, which would give scope for taking a calculated risk in their respective markets. It also provides scope for exploring cyclic or seasonal behaviour of these two markets independently. Among the various factors discussed that impact the GOI price markets, it can be derived that there is a limited impact due to GOFI markets. The presence of high volatility in freight markets gives an insight for exporters and importers to understand the risk in the markets and thereby comprehend the trade implications. The effect due to other factors like weather, financial growth, price of raw materials could be explored. As discussed 
in Kalkuhl, Braun, and Torero (2016), the effects due to other factors like trade policy, geographical, economic, political factors, consumption and cultivation patterns, weather effects, etc. could be studied to understand the impact on GOI.

\section{References}

[1] Alizadeh-M, A. H. (2013) 'Trading volume and volatility in the shipping forward freight market', Transportation Research Part E: Logistics and Transportation Review, Elsevier, 49(1), pp. 250-265. doi: 10.1016/j.tre.2012.08.001.

[2] Binkley, J. K. and Harrer, B. (1981) 'Major determinants of ocean freight rates for grains: an econometric analysis', American Journal of Agricultural Economics, Wiley, 63(1), pp. 47-57. doi: 10.2307/1239810.

[3] Ceballos, F. et al. (2017) 'Grain price and volatility transmission from international to domestic markets in developing countries', World Development, Elsevier, 94, pp. 305-320. doi: 10.1016/j.worlddev.2017.01.015.

[4] CME Group (2019) 'Understanding grains volatility and supply and demand', Introduction to Grains and Oilseeds. Available at: https://www.cmegroup.com/education/courses/introduction-to-grains-and-oilseeds/understandinggrains-volatility-and-supply-and-demand.html (Accessed: 25 September 2019).

[5] International Grain Council (2019a) Supply and Demand. Available at: https://www.igc.int/en/markets/marketinfosd.aspx (Accessed: 25 September 2019).

[6] International Grain Council (2019b) IGC Grains and Oilseeds Index. Available at: https://www.igc.int/en/markets/marketinfo-goi.aspx (Accessed: 25 September 2019).

[7] International Grain Counl (2019c) New IGC Grains and Oilseeds Freight Index. Available at: https://www.igc.int/ en/markets/marketinfo-freight.aspx (Accessed: 25 September 2019).

[8] David A. Dickey and Wayne A. Fuller (1981) 'Likelihood ratio statistics for autoregressive time Series with a unit root', Econometrica, Wiley, 49(4), pp. 1057-1072.

[9] Ding, X. et al. (2017) 'Long memory and scaling behavior study of bulk freight rate volatility with structural breaks', Transportation Letters, Taylor and Francis, 10(6), pp. 343353. doi: $10.1080 / 19427867.2016 .1270718$.

[10] Drobetz, W., Richter, T., and Wambach, M. (2012) 'Dynamics of time-varying volatility in the dry bulk and tanker freight markets', Applied Financial Economics, Taylor and Francis, 22(16), pp. 1367-1384. doi: 10.1080/09603107.2012.657349.

[11] Engle, R. (2002) 'Dynamic conditional correlation: A simple class of multivariate generalized autoregressive conditional heteroskedasticity models', The Journal of Business and Economic Statistics, American Statistical Association, 20(3), pp. 339-350. doi: 10.1198/073500102288618487.

[12] Fuller, S. et al. (2008) 'Effects of improving transportation infrastructure on competitiveness in world grain markets', Journal of International Food and Agribusiness Marketing, Taylor and Francis, 13(4), pp. 61-85. doi: 10.1300/ J047v13n04_05.

[13] Haigh, M. S. and Bryant, H. L. (2001) 'The effect of barge and ocean freight price volatility in international grain markets', Agricultural Economics (United Kingdom), Wiley, 25(1), pp. 41-58. doi: 10.1111/j.1574-0862.2001.tb00234.x.
[14] Hill, L., Lazarus, S., and Wiboonspongse, A. (2010) 'Risk and uncertainty in world grain markets', Agrekon, Taylor and Francis, 21(1), pp. 13-23. doi: 10.1080/03031853.1982.9524008.

[15] Hsu, J. L. and Goodwin, B. K. (1995) 'Dynamic relationships in the market for ocean grain freighting services', Canadian Journal of Agricultural Economics/Revue canadienne d'agroeconomie, Wiley, 43(2), pp. 271-284. doi: 10.1111/j.17447976.1995.tb00123.x.

[16] International Grain Council (2020) Grain Market Report. Available at: https://www.igc.int/en/default.aspx (Accessed: 21 January 2020).

[17] Ishizaka, M., Tezuka, K. and Ishii, M. (2018) 'Evaluation of risk attitude in the shipping freight market under uncertainty', Maritime Policy and Management, Taylor and Francis, 45(8), pp. 1042-1056. doi: 10.1080/03088839.2018.1463107.

[18] Jing, L., Marlow, P. and Hui, W. (2008) 'An analysis of freight rate volatility in dry bulk shipping markets', Maritime Policy and Management, Taylor and Francis, 35(3), pp. 237-251. doi: 10.1080/03088830802079987.

[19] Jonnala, S., Fuller, S., and Bessler, D. (2002) 'A GARCH approach to modelling ocean grain freight rates', International Journal of Maritime Economics, Palgrave, 4(2), pp. 103-125. doi: 10.1057/palgrave.ijme.9100039.

[20] Kalkuhl, M., Braun, J. von, and Torero, M. (2016) Food Price Volatility and Its Implications for Food Security and Policy, Springer Publishing House(Germany). doi: 10.1007/978-3319-28201-5.

[21] Kavussanos, M. G. and Alizadeh-M, A. H. (2001) 'Seasonality patterns in dry bulk shipping spot and time charter freight rates', Transportation Research Part E: Logistics and Transportation Review, Elsevier., 37(6), pp. 443-467. doi: 10.1016/S1366-5545(01)00004-7.

[22] Kavussanos, M. G., Visvikis, I. D. and Dimitrakopoulos, D. N. (2014) 'Economic spillovers between related derivatives markets: The case of commodity and freight markets', Transportation Research Part E: Logistics and Transportation Review, Elsevier, 68, pp. 79-102. doi: 10.1016/j.tre.2014.05.003.

[23] Li, K. X. et al. (2018) 'Dynamics and interdependencies among different shipping freight markets', Maritime Policy and Management, Routledge, 45(7), pp. 837-849. doi: 10.1080/03088839.2018.1488187.

[24] Lim, K. G., Nomikos, N. K. and Yap, N. (2019) 'Understanding the fundamentals of freight markets volatility', Transportation Research Part E: Logistics and Transportation Review, Elsevier, 130 (February), pp. 1-15. doi: 10.1016/j.tre. 2019.08.003.

[25] Lirn, T. C. and Wong, R. Der (2012) 'Determinants of grain shippers and importers freight transport choice behaviour', Production Planning and Control, Taylor and Francis 24(7), pp. 575-588. doi: 10.1080/09537287.2012.659868.

[26] Liu, J. and Chen, F. (2018) 'Asymmetric volatility varies in different dry bulk freight rate markets under structure breaks', Physica A: Statistical Mechanics and its Applications, Elsevier B.V., 505, pp. 316-327. doi: 10.1016/j.physa.2018.02.165.

[27] Miljkovic, D. et al. (2000) "The barge and rail freight market for export-bound grain movement from midwest to Mexican Gulf: An econometric analysis', Transportation Research Part E: Logistics and Transportation Review, Elsevier Ltd., 36(2), pp. 127-137. doi: 10.1016/S1366-5545(99)00025-3.

[28] Nelson, D. B. (1991) 'Conditional heteroskedasticity in asset returns: A new approach', Econometrica, Wiley, 59(2), pp. 347-370. 
[29] Rude, J. and An, H. (2015) 'Explaining grain and oilseed price volatility: The role of export restrictions', Food Policy, Elsevier, 57, pp. 83-92. doi: 10.1016/j.foodpol.2015.09.002.

[30] Santos, J. M. (2011) 'Trading grain now and then: The relative performance of early grain-futures markets', Applied Economics, Taylor and Francis, 45(3), pp. 287-298. doi: 10.1080/00036846.2011.597732.

[31] Tadesse, G. et al. (2016) 'Drivers and triggers of international food price spikes and volatility',Food Price Volatility and Its Implications for Food Security and Policy, pringer, Cham. pp. 59-82. https://doi.org/10.1007/978-3-319-28201-5_3.

[32] Thurman, B. K. and W. N. (2010) 'Components of grain futures price volatility', Journal of Agricultural and Resource Economics, Western Agricultural Economics Association, 35(2), pp. 167-182. doi: 10.9787/PBB.2013.1.1.024.
[33] Tsouknidis, D. A. (2016) 'Dynamic volatility spillovers across shipping freight markets', Transportation Research Part E: Logistics and Transportation Review, Elsevier, 91, pp. 90-111. doi: 10.1016/j.tre.2016.04.001.

[34] Veenstra, A. W. (1999) 'The term structure of ocean freight rates', Maritime Policy and Management, Taylor and Francis, 26(3), pp. 279-293. doi: 10.1080/030888399286899.

[35] Woodland, A. and Sen, K. (2010) 'The volatility of Australian traded goods' prices', Applied Economics, Taylor and Francis, 42(30), pp. 3849-3869. doi: 10.1080/00036840802360286.

[36] Wright, B. D. (2011) 'The economics of grain price volatility', Applied Economic Perspectives and Policy, Wiley, 33(1), pp. 32-58. doi: 10.1093/aepp/ppq033. 